HJIMB Vol 1, No. 2 2019, pp: 01- 05

https://doi.org/10.30606/hiimb

\title{
HIRARKI
}

Jurnal Ilmiah Manajemen dan Bisnis

http://iournal.upp.ac.id/index.php/Hirarki

\section{ANALISIS PENGARUH LIKUIDITAS TERHADAP MODAL KERJA PADA PD. BPR ROKAN HULU}

Andi Afrizal

Manajenem, Universitas Pasir Pengaraian

\section{Info Artikel}

Sejarah Artikel:

Diterima 23 Agustus

2019

Disetujui 16 September

2019

Dipublikasikan

30 Oktober 2019

Keywords: Modal Kerja, Likuiditas, Rokan Hulu

\begin{abstract}
Abstrak
Tujuan dari penelitian ini adalah untuk mengetahui apakah Likuiditas berpengaruh terhadap Modal Kerja. Penelitian ini dilakukan di PD. BPR Rokan Hulu yang beralamat di Jl.Tuanku Tambusai kompleks pasar modern kampung padang, Pasir Pengaraian Rokan Hulu-Riau. Alat analisis yang digunakan dalam penelitian ini adalah analisis linier sederhana dengan persamaan $Y=0,23+0,0006 X$. Serta analisis korelasi hasil penelitian ini menunjukkan bahwa terdapat pengaruh yang signifikan antara variabel $\mathrm{X}$ likuiditas dan Y modal kerja. Besar pengaruh tersebut ditunjukkan oleh nilai korelasi $\mathrm{r}$ sebesar $89 \%(0,89)$. Hubungan bersifat positif, yang artinya terjadi hubungan searah antara variabel $\mathrm{X}$ dan $\mathrm{Y}$.
\end{abstract}

ANALYSIS OF THE EFFECT OF LIQUIDITY ON WORKING CAPITAL IN PD. BPR ROKAN HULU

\section{Abstract}

The purpose of this study is to determine whether Liquidity affects Working Capital. This research was conducted in PD. BPR Rokan Hulu having its address on Jl. Tambkuai Tambusai modern market complex, padang village, Pasir Pengaraian Rokan Hulu-Riau. The analytical tool used in this study is a simple linear analysis with the equation $Y=0.23+0.0006 X$. As well as the correlation analysis of the results of this study indicate that there is a significant influence between variable $X$ liquidity and $Y$ working capital. The magnitude of this effect is shown by the correlation value of $r$ at 89\% (0.89). Relationships are positive, which means there is a direct relationship between variables $X$ and $Y$.

\footnotetext{
${ }^{\triangle}$ Alamat korespondensi :

Universitas Pasir Pengaraian

andiafriza107@gmail.com
} 


\section{PENDAHULUAN}

Kondisi bisnis sekarang ini menuntut perusahaan-perusahaan yang ada untuk senantiasa meningkatkan efisiensinya. Hal ini dimaksudkan supaya perusahaan dapat tetap bersaing dengan perusahaan-perusahaan lainnya. Pada dasarnya tujuan dari perusahaan ini adalah untuk memperoleh profit atau keuntungan yang maksimal dan berkelanjutan.

Pentingnya peranan dunia usaha dalam mewujudkan keinginan masyarakat maka setiap badan usaha (perseorangan, firma cv) harus memiliki posisi keuangan dan kinerja yang baik yang akan menjadi dasar bagi perusahaan untuk mempertahankan dan menjamin kelangsungan usahanya dimasa yang akan datang.

Modal kerja adalah investasi sebuah perusahaan pada aktiva-aktiva jangka pendek seperti kas persediaan dan piutang (Fahmi, 2013). Perusahaan pada dasarnya membutuhkan modal kerja yang cukup dalam menjalankan kegiatan operasionalnya. Uang atau dana yang dikeluarkan nantinya diharapkan akan dapat kembali lagi masuk kedalam perusahaan dalam waktu yang singkat. Dari laporan keuangan modal kerja nantinya akan sangat membantu dalam merencanakan dan melaksanakan penggunaan dana dengan sebaik-baiknya sehingga perusahaan bisa menghindari kekurangan dana yang nanti akan dapat menghambat pertumbuhan perusahaan.

Dari laporan sumber dan penggunaan modal kerja ini akan membantu manajer keuangan dalam melaksanakan kegiatan perusahaan dalam hal ini menentukan jumlah dana yang harus tersedia. Selain itu laporan tersebut juga membantu manajer keuangan dalam merencanakan berapa penggunaan dana dengan sebaik-baiknya untuk dapat menghindari hal-hal yang tidak diinginkan perusahaan apabila perusahaan kekurangan dana tentu akan sulit berkembang.

Kebijakan perusahaan dalam mengelola jumlah modal kerja secara tepat akan mengakibatkan keuntungan, sedangkan akibat dari penanaman modal kerja yang kurang tepat akan mengakibatan kerugian. Agar dapat menilai posisi keuangan suatu perusahaan dalam menyelesaikan kewajiban-kewajibannya, maka perlu digunakan alat analisis yang dinamakan rasio likuiditas, artinya rasio yang menggambarkan kemampuaan suatu perusahaan dalam memenuhi kewajiban jangka pendeknya secara tepat waktu (Fahmi, 2013). Dari perhitungan rasio ini diharapkan dapat membatu para manejer untuk menilai efisiensi modal kerja yang digunakan perusahaan dalam menjalankan usahanya. Analisis rasio terhadap modal kerja perusahaanpun sangat perlu dilakukan untuk mengetahui dan menginterprestasikan posisi keuangan jangka pendek perusaan serta meneliti efisiensi dan penggunaan modal kerja terhadap perusahaan (Susanti, 2012).

Usaha yang dilakukan untuk mempertahankan dan mengembangkan PD. PBR Rokan Hulu yaitu pengelolaannya yang harus dilakukan secara profesional dengan mempertimbangkan aspek-aspek yang mendukung kelangsungan hidup perusahaan dimasa yang akan datang. Adapun salah satu aspek yang perlu diperhatikan dalam menjalankan perusahaan adalah tingkat likuiditas yang dicapai PD. BPR Rokan Hulu.

PD. BPR Rokan Hulu dapat dimanfaatkan masyarakat kecil dan menengah terutama masyarakat yang mempunyai sektor rill dan untuk organisasi dan koperasi. Selain itu membantu program pemberdayaan desa (PPD) kabupaten Rohul.

PD. BPR Rokan Hulu adalah lembaga keuangan bank milik pemerintah kabupaten Rokan Hulu yang sahamnya $100 \%$ dimiliki kabupaten Rokan Hulu. Adapun jenis produk yang ada dalam bank ini adalah tabungan deposito, dan kredit. Bank masih memiliki satu jaringan kantor yaitu kantor pusat yang beralamat di Jl.Tuanku tambusai, Komplek Pasar Modern Kampung Padang Pasir Pengaraian Rokan Hulu-Riau. Dasar pendirian PD. BPR Rokan Hulu adalah perda kabupaten Rokan Hulu No. 03 tahun 2007 tentang pendirian PD. BPR Rokan Hulu serta surat keputusan Bank Indonesia No.9/33/KEP/GBI/DP9/2007, tentang izin operasional PD. BPR Rokan Hulu.

Likuiditas berhubungan dengan masalah kemampuan suatu bahan usaha untuk memenuhi kebutuhan finansialnya yang harus dipenuhi. Tingkat likuiditas dan faktor-faktor mempengaruhinya perlu diperhatikan oleh pihak interen perusahaan sebagai dasar untuk menentukan kebijakan bagi perkembangan suatu badan usaha dari tahun ketahun. Tingkat likuiditas bagi PD. BPR Rokan Hulu yaitu untuk mengetahui apakah PD. BPR Rokan Hulu memerlukan uang yang cukup dipergunakan secara lancar dalam menjelaskan usahanya.

Pada Tabel berikut menjelaskan rincian modal kerja PD. BPR Rokan Hulu dari tahun 20102014.

Tabel 1.1

Jumlah Modal Kerja PD. BPR Rokan Hulu

\begin{tabular}{|c|c|c|}
\hline No & Tahun & Modal Kerja \\
\hline 1 & 2010 & Rp. 5.800 .000 .000 \\
\hline 2 & 2011 & Rp. 8.300 .000 .000 \\
\hline
\end{tabular}




\begin{tabular}{|c|c|c|}
\hline No & Tahun & Modal Kerja \\
\hline 3 & 2012 & Rp. 8.300 .000 .000 \\
\hline 4 & 2013 & Rp. 8.300 .000 .000 \\
\hline 5 & 2014 & Rp. 8.300.000.000 \\
\hline
\end{tabular}

Sumber Data: Laporan Keuangan PD. BPR Rokan Hulu

\section{METODE}

Teknik sampling dalam penelitian ini menggunakan metode purposive sampling adalah teknik penentuan sampel dengan pertimbangan tertentu (Sugiyono,2012:122). Adapun pertimbangan sampel yang akan digunakan yaitu Laporan keuangan yang publikasi lima tahun terakhir. Jenis data yang digunakan adalah data kuantitatif, merupakan data yang terdiri dari kumpulan angka angka atau data-data perusahaan yang berhubungan dengan keuangan.

\section{HASIL DAN PEMBAHASAN}

Untuk mencari persamaan regresi linier sederhana dibutuhkan tabel penolong, adapun tabel penolongnya adalah sebagai berikut:

Tabel 4.7

Tabel penolong untuk mencari konstanta a dan

\begin{tabular}{|c|c|c|c|c|}
\hline Tahun & X & Y & XY & $\mathrm{X}^{2}$ \\
\hline 2010 & 1003,77 & 0,75 & 752,83 & 1007554,2 \\
\hline 2011 & 628,87 & 0,63 & 396,19 & 395477,47 \\
\hline 2012 & 687,7 & 0,79 & 543,28 & 472931,29 \\
\hline 2013 & 630,09 & 0,59 & 371,75 & 397013,4 \\
\hline 2014 & 209,32 & 0,30 & 62,77 & 43781,38 \\
\hline$\Sigma$ & 3159,67 & 3,06 & 2126,82 & 2316757,5 \\
\hline
\end{tabular}

a.

$$
\text { Sumber: Data Olahan }
$$

menghitung Nilai Konstanta a dan b

1. Menghitung nilai konstanta (b)

$$
\begin{aligned}
b & =\frac{n \cdot \Sigma X Y-\Sigma \times \cdot \Sigma Y}{n \cdot \Sigma X^{2}-(\Sigma X)^{2}} \\
b & =\frac{5 \cdot 2126,82-3159,67 \cdot 3,06}{5.2316757,5-(3159,67)^{2}} \\
b & =\frac{965,48}{1600273} \\
b & =0,006
\end{aligned}
$$

2. Menghitung nilai konstanta (a)

$$
\begin{aligned}
& a=\frac{\Sigma Y-b \cdot \Sigma X}{n} \\
& a=\frac{3,06-0,006 \cdot 3159,67}{5} \\
& a=\frac{1,15}{5} \\
& a=0,23
\end{aligned}
$$

3. Membuat persamaan regresi linier sederhana

$$
\begin{aligned}
& Y=\mathrm{a}+\mathrm{b} \cdot \mathrm{x} \\
& Y=0,2 \mathrm{X}
\end{aligned}
$$

Dari hasil yang diperoleh diatas, maka dapat disimpulkan bahwa terdapat hubungan positif antara variabel $\mathrm{X}$ likuiditas dan $\mathrm{Y}$ modal kerja, dengan persamaan $\mathrm{Y}=0,23+$ 0,006X artinya konstanta a menyatakan bahwa setiap satu satuan Rp 1,00 likuiditas mengalami peningkatan sebesar 0,006 likuiditas yaitu Rp 0,006, semakin tinggi naik likuiditas maka akan berpengaruh terhadap modal kerja.

a. Menghitung koefisien korelasi (r)

Tabel 4.8

Tabel mencari nilai korelasi (r)

\begin{tabular}{|c|c|c|c|c|c|}
\hline Tahun & $\mathrm{X}$ & $\mathrm{Y}$ & $\mathrm{XY}$ & $\mathrm{X}^{2}$ & $\mathrm{Y}^{2}$ \\
\hline 2010 & 1003,77 & 0,75 & 752,83 & 1007554,2 & 0,56 \\
\hline 2011 & 628,87 & 0,63 & 396,19 & 395477,47 & 0,4 \\
\hline 2012 & 687,7 & 0,79 & 543,28 & 472931,29 & 0,62 \\
\hline 2013 & 630,09 & 0,59 & 371,75 & 397013,4 & 0,35 \\
\hline 2014 & 209,32 & 0,30 & 62,77 & 43781,38 & 0,09 \\
\hline$\Sigma$ & 3159,67 & 3,06 & 2126,82 & 2316757,5 & 2,02 \\
\hline
\end{tabular}

Sumber: Data Olahan

n. $\mathrm{XXY}-\Sigma \mathrm{X} \cdot \mathrm{\Sigma} x$

$$
\begin{aligned}
& r=\frac{}{\sqrt{\left[n, \Sigma x-\left(2 x^{2}\right)\right\}\left(n \Sigma Y^{2}-\left(\Sigma Y^{2}\right)\right.}} \\
& r=\frac{5.2126,82-3159,67.3,06}{\sqrt{\left[5.2316757,5-\left(3159,67^{2}\right)\right\}\left[5(2,02)-\left(3,06^{2}\right)\right.}} \\
& r=\frac{10634,1-9668,62}{\sqrt{(11583787-9983514,5)\} 10,1-9,36)}} \\
& r=\frac{965,48}{\sqrt{(1600273)(0,74)}} \\
& r=\frac{965,48}{\sqrt{1184202}} \\
& r=\frac{241,38}{272,02}
\end{aligned}
$$$$
r=0,89
$$

Dari hasil perhitungan diatas didapat nilai $r$ adalah 0,89 yang berarti mendekati +1 , setelah melakukan pengukuran hubungan 
antara likuiditas dengan modal kerja ternyata positif sangat kuat karena nilai $r$ sebesar 0,89 . Hubungan yang bersifat positif artinya terjadi hubungan searah antara $\mathrm{X}$ dan $\mathrm{Y}$, dengan demikian dapat disimpulkan hubungan kedua variabel sangat kuat.

\section{b. Mengitung Koefisien Determinasi (KD)}

$$
\begin{aligned}
& \mathrm{KD}=(\mathrm{r})^{2} \times 100 \% \\
& \mathrm{KD}=(0,89)^{2} \times 100 \% \\
& \mathrm{KD}=0,79 \times 100 \\
& \mathrm{KD}=79 \%
\end{aligned}
$$

Dari hasil hitung $\mathrm{r}^{2}$ dari likuiditas terhadap modal kerja adalah 79\%. Dimana sebelumnya $r$ adalah 0,89 yang menunjukkan hubungan yang sangat kuat antara variabel $X$ terhadap variabel $\mathrm{Y}$, kemudian dijadikan ke $\mathrm{r}^{2}$ yaitu menjadi 0,79 yang menunjukkan kuatnya hubungan antara variabel $\mathrm{X}$ dan $\mathrm{Y}$ setelah itu dijadikan kebentuk persen $79 \%$ dan sisanya $21 \%(100 \%-79 \%)$ adalah variasi dari variabel independen (likuiditas) yang mempengaruhi variabel dependen (modal kerja).

\section{c. Uji Hipotesis secara Parsial (Uji t)}

a. Menghitung thitung

thitung

$$
=\frac{0,89 \sqrt{5-2}}{\sqrt{1-(0,79)}}
$$

b. Menghitung $t_{\text {tabel }}$

$$
\begin{aligned}
\mathrm{t}_{\text {tabel }} & =\mathrm{t}_{(\mathrm{a} / 2)(\mathrm{n}-2)} \\
& =\mathrm{t}_{(0,05 / 2)(5-2)} \\
& =\mathrm{t}_{(0,025)(3)} \\
& =3,182
\end{aligned}
$$

Tujuan membandingkan antara $t_{\text {hitung }}$ dan $t_{\text {tabel }}$ adalah untuk mengetahui apakah Ho ditolak atau diterima berdasarkan pengujian:

$t_{\text {hitung }} \geq t_{\text {tabel }}(3,35 \geq 3,182)$, maka Ho ditolak

Keputusannya adalah menyatakan karena $t_{\text {hitung }}$ lebih besar dari $t_{\text {tabel }}$ maka Ho ditolak sehingga Ha diterima, artinya bahwa ada pengaruh yang signifikan antara likuiditas dengan modal kerja yaitu antara variabel $\mathrm{X}$ dan $\mathrm{Y}$.

\section{SIMPULAN DAN SARAN}

Berdasarkan dari analisis keuangan yang dilakukan terhadap PD. BPR Rokan Hulu yang berkaitan dengan pengaruh likuiditas terhadap modal kerja dapat disimpulkan:

1. Terdapat pengaruh yang signifikan antara variabel $\mathrm{X}$ likuiditas dan variabel $\mathrm{Y}$ modal kerja. Besar pengaruh tersebut ditunjukkan oleh nilai korelasi r sebesar 0,89 yaitu (89\%) dan $r^{2} 0,79$ yaitu (79\%). Hubungan bersifat positif, yang artinya terjadi hubungan yang searah antara variabel $\mathrm{X}$ dan $\mathrm{Y}$.

2. Berdasarkan uji $\mathrm{T}$ didapat $\mathrm{T}_{\text {hitung }} \geq \mathrm{T}_{\text {tabel }}$ sehingga Ho tidak diterima dan $\mathrm{H}_{\mathrm{a}}$ ditolak. Dengan demikian terdapat pengaruh yang signifikan antara likuiditas dengan modal kerja

3. Rasio Banking Ratio dan Cash Ratio PD. BPR Rokan Hulu pada tahun 2010-2014 berada jauh diatas standar yang artinya rasio tergolong baik dan terus pertahankan.

\section{Saran}

1. Masalah akan dapat segera diketahui dan dicari pemecahannya dari penggunaan modal kerja, sehingga bisa segera diatasi. Misalnya, dapat dilihat dari keuntungan dan kerugian yang didapat PD. BPR Rokan Hulu. Dari masalah tersebut dapat dilihat efisien tidaknya pengelolaan modal kerja pada perusahaan yang bersangkutan.

2. Penelitian ini hanya menggunakan data selama selama 5 tahun yaitu 2010-2014. Untuk peneliti selanjutnya sebaiknya jumlah data diperbanyak agar penelitian semakin kuat.

3. Bagi peneliti selanjutnya sebaiknya menambah jumlah variabel dan tidak hanya menggunakan indikator Quick Ratio, Banking Ratio, Assets to Loans Ratio, Cash Ratio, agar lebih efisien.

\section{DAFTAR PUSTAKA}

Atmaja, Lukas Setia. 2008. TeoridanPraktikManajemenKeuangan. Yogyakarta: CV. Andi

Fahmi, Irham. 2013. AnalisisLaporanKeuangan. Bandung: Alfabeta

Harahap, SofyianSyafri. 2010. AnalisisKritisAtasLaporanKeuangan. Jakarta: PT. Raja GrafindoPersada.

Harjito, $\quad 2011$. ManajemenKeuanganEkonisia. Yogyakarta.

Kasmir. 2012. AnalisisLaporanKeuangan. Jakarta: PT. Raja GrafindoPersada.

Kasmir 2013. AnalisisLaporanKeuangan.Jakarta:PT. Raja GrafindoPersada. 
Mahfudlian,Ita.

2010.AnalisisPengaruhEfesiensi Modal

Kerjaterhadap Tingkat Likuiditas Perusahaan

Manufaktur yang Terdapat di Bursa Efek Indonesia.

Munawir. 2004. AnalisisLaporanKeuangan. Yogyakarta: Liberty

RizaWahyuAinurRobbi. 2010. Efisiensi Modal KerjauntukMeningkatkanProfitabilitas Perusahaan. Malang.

Siregar, $\quad$ Syofian. 2013. StatistikaParametikuntukPenelitianKuantitatif. Jakarta: PT. BumiAksara.

Siwi. 2007. AnalisisPengaruhEfesiensi Modal Kerja, Likuiditas, SolvabilitasterhadapProfitabilitaspada

Perusahaan Property dan Real Etel yang Go Public di Bursa Efek Jakarta Tahun 19982002. Jakarta.

Soemarso. 2005. AkuntansiSuatuPenganta. Jakarta: SalembaEmpat.

Subramanyamdan John, Wild. 2010. AnalisisLaporanKeuangan. Jakarta: SalembaEmpat.

Sudjada. 2005. MetodeStatistika.EdisiKeenam. Bandung: Tarsito.

Zainuddin, $\quad$ Ahmad. 2013. AnalisisPengaruhLikuiditasterhadap Modal Kerjapada CV. TeguhGemilang. Cirebo 